\title{
Prospects for the socio-economic development of a small urban settlement
}

\author{
Ekaterina Alpatova ${ }^{1, *}$, Elena Semak ${ }^{2}$, Vardan Nikogosyan ${ }^{3}$, Svetlana Tekucheva ${ }^{4}$, and \\ Yuliya Merinova ${ }^{5}$ \\ ${ }^{1}$ State University of Management, 109542 Ryazan Ave., 99, Moscow, Russia \\ ${ }^{2}$ Republican Institute of Higher Education, 220007 Moskovskaya str., 15, Minsk, Belarus \\ ${ }^{3}$ Rostov State Economic University (RINH), 344002 Bolshaya Sadovaya Street, 69, Rostov-on-Don, \\ Russia \\ ${ }^{4}$ Don State Technical University, 344003 Gagarin Sq., 1, Rostov-on-Don, Russia \\ ${ }^{5}$ Southern Federal University, Institute of Earth Sciences, 344090 Sorge Street, 40, Rostov-on-Don, \\ Russia
}

\begin{abstract}
The article is devoted to the design idea the concept of the universal project of socio-economic development of small urban settlement on the example of single-industry towns of the South of Russia, and highlighted relevant data problems of urban agglomerations, the ways of contributing to the solution, as the demographic situation and migration of the working population, creation of new jobs through attracting investors and foreign workers to solve problems such areas having a similar nature and roots throughout the territory of the Russian Federation. The work is a strategic vector of the concept for the socio-economic development of economically unprofitable territories of the Russian Federation based on the use of the TRIZ system operator. The concept of the project allows us to demonstrate the way of possible transformation of the economy of economically unprofitable regions. The paper formulates the goal of socioeconomic development for a small urban settlement, forms the ways of strategic transformation, analyzes the current situation, identifies the main problems and suggests a possible vector for the development of the territory based on the development of production, infrastructure, the quality of the urban environment and the use of the climatic and cultural features of the region.
\end{abstract}

\section{Introduction}

The relevance of implementing socio-economic development projects for small urban settlements is growing every year. In search of higher wages and jobs, the adult workingage population of small urban agglomerations leaves their native lands, rushing to the cities of millions and the capital of the Russian Federation. Due to the fact that the territory of the Russian Federation consists of $45 \%$ of various types of single-industry towns, including small urban settlements, the problem of the development of these territories is of both a

\footnotetext{
* Corresponding author: katrin.alpatova@mail.ru
} 
macroeconomic and a macrosocial format. The main population of small towns consists of elderly people and schoolchildren left by their parents in their care, while parents are forced to work on a shift basis to provide for the abandoned family (old people and children) in small settlements. On average, for 10,000 residents of small towns, the working-age population ranges from 350 to 500 people, which is an indicator of a "dying" unpromising, economically unprofitable city. The massive outflow of labor from small towns has led to the fact that almost all projects proposed by the administration for the development of the economy of these territories face the fact that there is no required amount of labor for the implementation of potential projects of socio-economic development. To solve the problem of "emptying" small urban agglomerations government developed various funds to maintain and develop the quality of the urban environment, but to the authors, the root of all evil, to effectively address global issues related to the development of small towns is seen in other - without the revival of the production sector of these territories as the basis for shaping the future development and prosperity in the future.

\section{Materials, Methods and Results}

\subsection{The basis for the idea of the concept of socio-economic development}

The search for an investor for the implementation of major industrial projects in the territory of the South of Russia not long in coming: a large amount of free land in the towns, with a depressed economy; huge areas of agricultural land, poorly used because of the collapse of the Soviet legacy of kolkhozes and sovkhozes in the sphere of agriculture and livestock; a favourable climate with mild climate in winter with plus temperatures; low rent of land; an extensive network of gas and electricity, highway with a quality road surface; convenient logistics and transport hubs, and more.

\subsection{Application of the SMART methodology for the formation of the general goal of the project concept}

The SMART method allows you to formulate a goal that is possible for successful implementation. According to the" decoding " of the acronym (abbreviation) of this technique, the goal must meet several criteria in order to be successfully implemented: Sconcreteness, M-measurability, A-achievability, R-relevance, T-time limitation. Thus, the goal of the project of socio-economic development of a small urban settlement will sound like this:

"Creation of a large socio-economic facility for the organization of additional jobs (from 500 to 1000 people), contributing to the influx of the working-age population and the exit of the economy of a small urban settlement from an economically depressed state by the end of 2023."

If we consider the criterion approach according to the SMART method [1-2] to the goal formulated for the project concept, then, based on obviously visible reasons, there is a dilemma about the presence in the internal potential of small urban agglomerations of a large number of free labor resources for the implementation of such an ambitious goal in life. It is proposed to use the "ladder of questions" methodology [3-4] from the coaching methods, where the priority question for the formation of the general goal of the project concept will be the following question: "Where in the world are the resources necessary for the successful implementation of the project?» The answer to this question is determining the amount of labour from the experiences of the global economy use the "cheap" labor of 
East Asian countries (India, China etc.) and economically unstable former Soviet republics (Tajikistan, Kyrgyzstan, Uzbekistan, etc.). Thus, there is an expansion of the general goal of the project concept for the socio-economic development of a small urban settlement: "The creation and commissioning of a large production socio-economic facility with the involvement of foreign labor (at the initial stage of launch) in the amount of 500 to 1000 people, which will further contribute to the "return" of the able-bodied local population and the exit from the crisis economic state of the urban agglomeration by the end of 2023".

Especially the demographic problem with the size of the working-age population is typical for single-industry towns, which actually grew up around a large industrial mining facility or industrial enterprise. After the historical period of the collapse of the Soviet Union, many of these towns began to fade, as they lost state support or mining dried up and mines closed, which is typical for single-industry towns in the South of Russia. Currently, there are a sufficient number of such "dying" urban settlements in the South of Russia, which are in a stagnant state, in fact, in an economic depression. One example is the singleindustry town of Zverevo, located in the Rostov region. In this single-industry town, about $97 \%$ of the city budget is the income from the successful operation of the mine with hydrocarbons, according to scientists, the reserve of useful hydrocarbons is 30 years, i.e. in three decades this town will disappear along with the reserve of minerals in the mine of the city. As a measure to reanimate the economy and develop the strategic vector of the city, the administration of the city settlement took the initiative to create a comfortable park recreation area for the residents of the city. This, of course, improved the appearance of a typical post-Soviet town, but in no way affected the creation of mass additional jobs and the "return" of the working-age population from the cities of millions and the capital of Russia.

\subsection{Formation of the future state of a small urban settlement according to the concept of the project of economic and social development}

It is possible to predict the future state of economic objects by using the matrix of talented thinking (the system operator of the Theory of Inventive problem solving (TRIZ)) [5-7]. The principle of construction of the system operator is to describe in detail the components of the supersystem (that is, in fact, the maximum number of items in the macro environment social object), subsystems (elements that form the basis of the functioning of the object of study), system (which represents the object of study) in the ratio of pastpresent-future, given the tendency of change from past to present and broadcasting it for the future object of study, but with additional requirements of modernity.

Thus, to determine the future state, it is necessary at the initial stage to consider such socio-economic objects in the time lag-50-70 years, then describe the state of the object of study in the present time period, and then transpose these states (from the past to the present) for the future period of the object of study. Using this TRIZ tool [5-7], it is possible to form a strategic development vector for a typical small urban settlement (Fig. $1)$. 


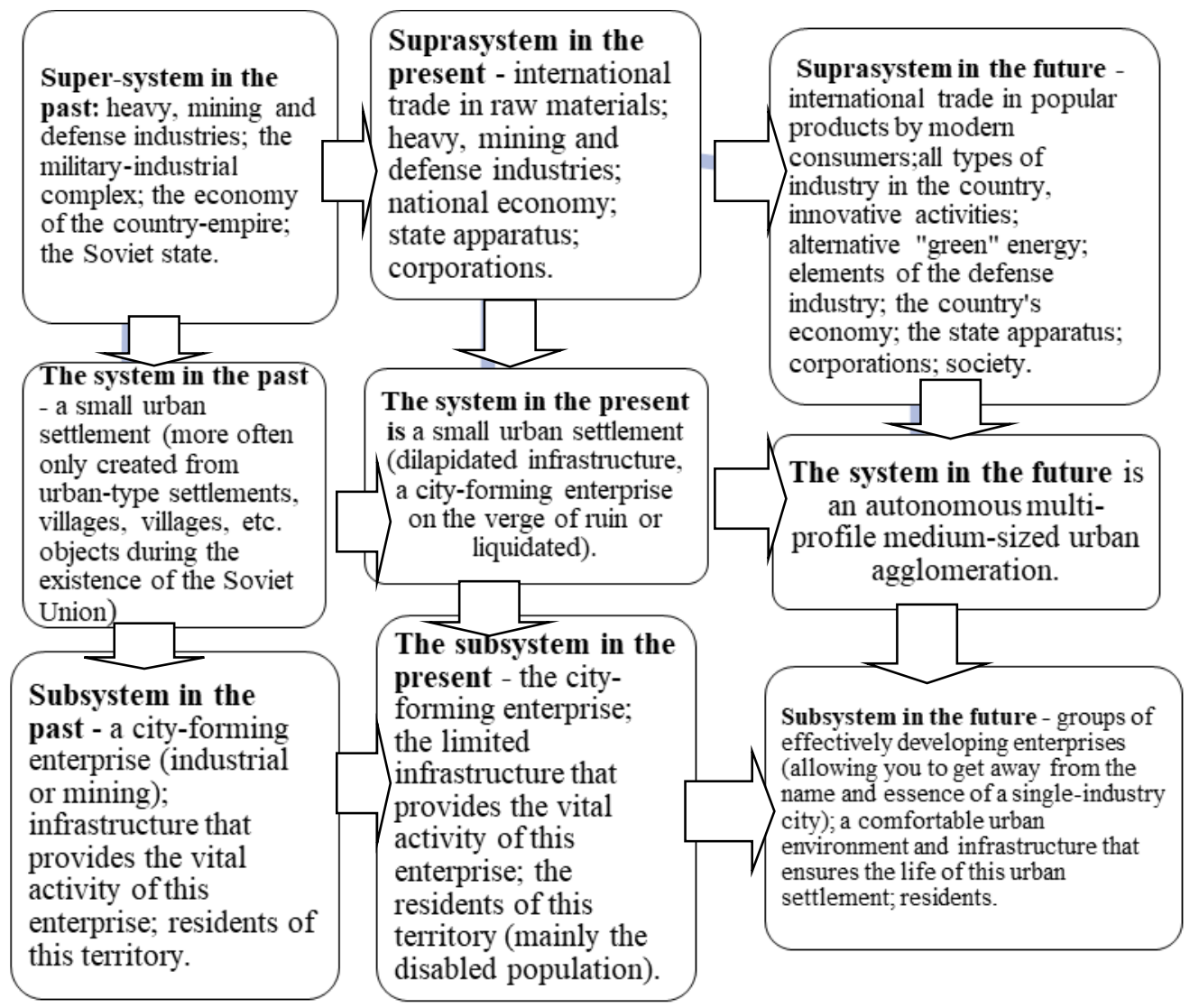

Fig. 1. System operator for designing the future state of a small urban agglomeration.

Past - 50s of the 20th century: (the time lag is 70 years).

Object (system) - a small urban settlement (most often only created from urban-type settlements, villages, villages, etc. objects during the existence of the Soviet Union).

The main functions of the object:

1) an element of global Soviet industrialization;

2) an element of support for the extraction of minerals to meet the needs of the developing

Soviet heavy industry;

3 ) the element of creating the world's largest military-industrial complex of the USSR.

According to the imperial state goals, industrial single-industry towns began to be formed artificially from a mass number of agricultural regions, as part of the" road map " above the stipulated state requirements, in fact, coinciding with the functionality of the research objects.

The super-system of such an object in space was composed of:

1) heavy industry;

2) mining industry;

3) the defense industry;

4) military-industrial complex;

5) the economy of the country-empire;

6) the Soviet state.

The super-system of such an object by function was:

1) NTP (scientific and technological progress and foreign innovative technologies); 
2) the system of education (secondary, compulsory for all residents of the USSR), as a potential for the development of a higher-class workforce capable of mastering advanced world technologies, and education (in the spirit of communist ideals);

3) the Communist Party of the USSR (as a state doctrine);

4) the army of the USSR.

The subsystem of this object consisted of:

1) a city-forming enterprise (industrial or mining minerals);

2) infrastructure that ensures the life of the enterprise:

- administrative bodies;

- various stores;

- fast food facilities;

- leisure and recreation facilities;

- educational professional institutions, and, necessarily in the direction of the cityforming enterprise, (since one of the goals of creating a single-industry town or small urban settlement with an industrial center, of course, was the idea of an uninterrupted supply of labor resources for the "central" enterprise);

- schools;

- preschool institutions and other socially significant objects;

3) residents of the given territory.

The transformation into the state in which a small urban settlement with an industrial center currently exists is caused by the alienation of the goals of the recipient state (Russia from the USSR) of global goals, in fact, forming a military empire. Thus, the impact on transformation using the TRIZ method - the system operator [5-7], It is necessary to start from the opposite goals of the state level, if the task of reviving small urban agglomerations is set, or to look for a new global solution. Thus, the doctrine of creating the largest network of single-industry towns with a large industrial center was necessary to maintain the status of a major military-industrial power in the world. At present, the state policy has shifted from pacifist sentiments and is moving towards the re-establishment of a military empire, as a vector of socio-economic development, this can become the basis for maintaining this goal. However, in the modern world, there are several new generations of people at the same time [8], which makes new demands on the formation of state doctrines. If the generation of "silent", "baby boomers" and " $\mathrm{X}$ " were confirmed collectivist management, generation "Y", "Z" and then the generation of " $\alpha$ " basically show the uniqueness, usefulness of life on the prevalence of wages, finding ways for selfdevelopment, a special attitude to the ecology of the planet, etc. Then, given this knowledge about the essence of the core of generations, it is worth forming a new vector of statehood, or it will not be implemented as in the previous 40-30 years. Nevertheless, the" transformation "of a loss-making agricultural territory into a prosperous industrial" paradise $"$ is possible if the goal is aimed at the socio-economic development of small urban agglomerations, coupled with the development of the industrial level. That is, we should avoid the mistakes of the Soviet nomenclature associated with the inflection of the management style towards " business efficiency "(9), which we can observe in the state of these urban agglomerations: poor quality of infrastructure for the residents of these territories, lack of cultural and leisure recreation, low standard of living, lack of selfdevelopment, wages at the level of survival, widespread drunkenness.

Present (2020)

Object (system) - a small urban settlement (dilapidated infrastructure, city-forming enterprise on the verge of ruin or liquidated).

The main functions of the object:

1) an element of the legacy of Soviet industrialization; 
2) the element of support for the extraction of minerals partly to support the needs of the Russian industry, and in most cases, for sale abroad (for example, in the city of Zverevo, Rostov region, $100 \%$ of the anthracite coal produced in the territory of the Zverevsky district is sold in Western Europe);

3) a small homeland, for a huge number of migrating working-age population in search of higher wages and jobs.Currently, there are "near-death" convulsions of such territories: the destruction of poor infrastructure, a sharp reduction in residents, a low standard of living, etc.

Social policy should be directed to global restructuring of views on the essence of small urban areas, and single-industry towns in Russia to an average of 45\% (10), this is a huge, economically complex formation, requiring immediate government intervention, otherwise, it will continue to negatively relate to demography of the country in General and the fall of the gross domestic product in the short term. Part of the "road map" should be the idea of introducing new (modernized) production facilities, for the "return" of local labor resources to the small homeland and filling its demographic and economic "gaps".

The super-system of a small urban settlement currently consists of:

1) international trade in raw materials (minerals) to Western European countries, etc.;

2) heavy industry;

3) mining industry;

4) elements of the defense industry;

5) the country's economy;

6) the state apparatus;

7) of the Corporation.

The super-system by function consists of:

1) NTP (scientific and technological progress and foreign innovative technologies);

2) the army of the Russian Federation;

3) the appearance of cities with Soviet buildings, the housing stock of the Soviet period, in general, (with the exception of Moscow and, in part, St. Petersburg)

The subsystem consists of:

1) a city-forming enterprise (industrial or mining) in a pre-crisis state or liquidated, (then only physical buildings of the former industrial facility);

2) limited infrastructure that ensures the life of the enterprise:

- administrative bodies;

- limited number of stores;

- fast food facilities;

- leisure and recreation facilities;

- educational professional institutions in the direction of the city-forming enterprise, (as a post-Soviet heritage, irrelevant at the present time, the "ossification" of these structures, a limited choice of specialties and a professional base for teaching working specialties);

- schools;

- preschool institutions and other socially significant objects;

3) residents of the given territory (mainly the disabled population-pensioners and schoolage children).

Thus, when applying the "past-present" vector, the object of study will be completely physically destroyed. For the current development vector, it is necessary to be guided by the goals based on the "organization" management style, namely, the compromise direction on "business efficiency" (the introduction of new large industrial facilities into operation), and on "taking care of people" (the creation and maintenance of high-quality infrastructure in the territories of small urban settlements). A positive example in the modern economy is the revival of the city of Moscow. Tikhvin, Leningrad region, having received a serious investment for industrial development, workforce was drawn from the largest Russian 
company towns of Togliatti, where, despite continuous state support, the decline of production, and hence the reduction of jobs and quality of life of the population. The city administration is headed for the style of "organization" and, together with the introduction of a special programme for the relocation of new workers have made many efforts on creation of a comfortable urban environment in the form of new roads, parks, construction of a new neighborhood, the introduction of a preferential mortgage loans when applying for a new industrial plant. Such a massive social policy led to very good results: the entire map of goals for the urban agglomeration was completed and the city got out of both the demographic hole and the economic crisis, in addition, a large tourist trump card of this single-industry city, a former ancient city, was used in this object, a grant was allocated for the restoration of the old wooden city center, which now attracts additional funds from the tourist flow. Thus, in the future, the object of research (the system of a small urban settlement) should be an economically autonomous entity with a mandatory industrial center, (but not for the development of the military-technical complex or other imperial purposes), but most likely, products that are in demand, both in the domestic and foreign markets, allowing to implement the idea of a free market. As well as the mandatory consideration of a comfortable urban environment, so that the younger generation does not seek to leave their small homeland, but has the opportunity to get an education, a decent salary and a high standard of living, and continue to live in a small urban settlement. The third vector of success of a small urban settlement of the future is the use of the potential of the location region-natural conditions (forest, steppe, hills, river, mountains, snowy (mild) winter, hot summer, old buildings or an industrial abandoned area for the implementation of popular "stressful" quests or industrial mountaineering, urban legends, special traditions or cuisine that will form the basis, for example, for activation, relevant in the present time, (new coronavirus pandemic), domestic tourism. Thus, in addition to creating a "real" sector of the economy - new objects of city-forming enterprises and a qualitatively new level of infrastructure for the residents of the settlement, it is necessary to develop measures related to advertising and PR campaigns to create an additional vector of socio-economic development of a small urban agglomeration.

The future (around 2090).

The system is an autonomous multi-disciplinary medium-sized urban agglomeration.

Assumed main functions of the object:

1) a modern smart city [11-12] with a developed infrastructure and several efficient areas of public production;

2) a city with alternative energy sources [13] (for example, for the South of Russia, the use of wind and solar is climatically advantageous);

3) a comfortable eco-environment for residents who want to live their lives in their hometown.

The super-system of an average urban settlement in the future (in space) is (Fig. 2):

1) international trade in high-demand products by modern consumers;

2) all types of industry in the country, innovation activities;

3) an alternative "green" energy;

4) elements of the defense industry;

5) the country's economy;

6) the state apparatus;

7) corporations;

8) society.

The supersystem (by function) is expected to be formed:

1) NTP (scientific and technological progress and foreign innovative technologies);

2) digitalization of the region's economy [14];

3) innovative technology development centers, business incubators, etc. 


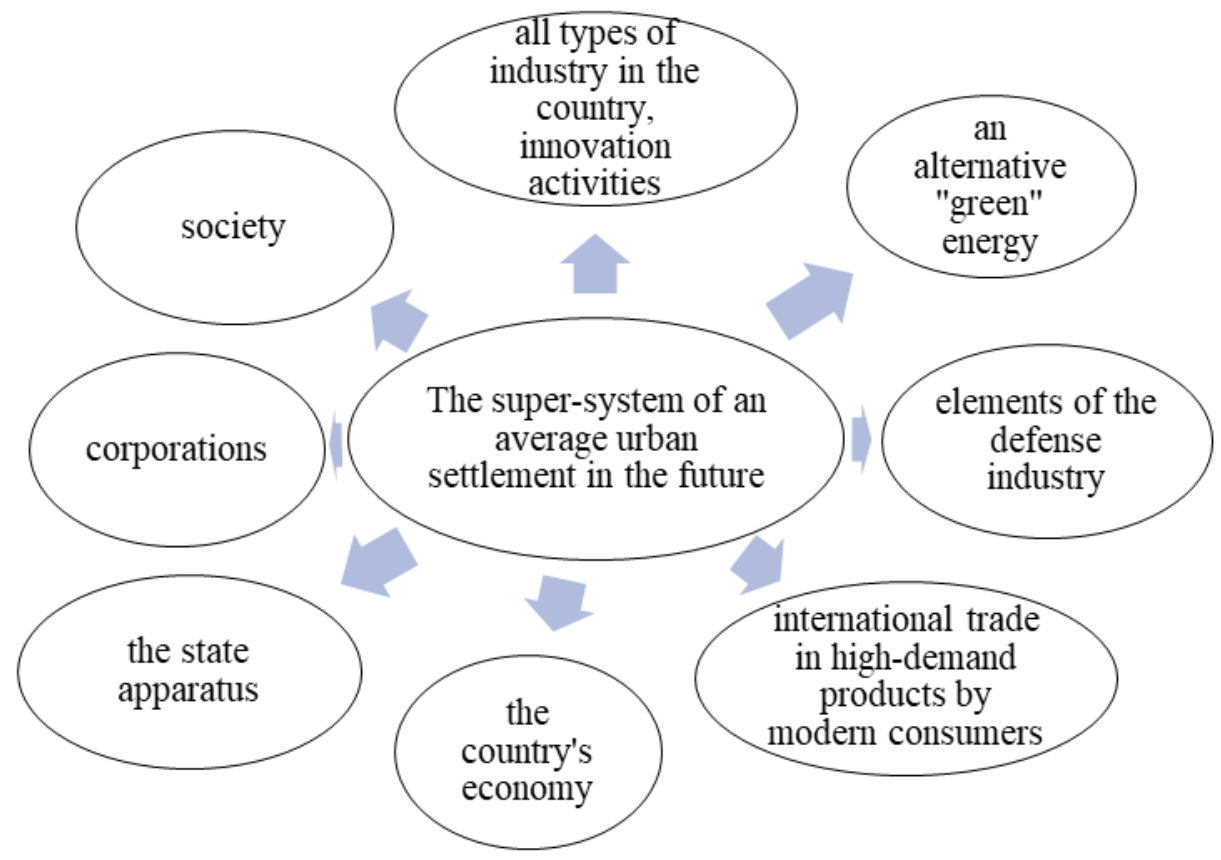

Fig. 2. The projected super-system of an average urban settlement in the future (in space)

The subsystem consists of:

1) groups of effectively developing enterprises (allowing you to get away from the name and essence of a single-industry city) $(15,16)$;

2) a comfortable urban environment and infrastructure that ensures the vital activity of this urban settlement:

- administrative bodies;

- stores;

- fast food facilities;

- leisure and recreation facilities;

- educational professional institutions on the demand for professions in the labor market;

- schools;

- preschool institutions and other socially significant objects;

3) residents of the given territory.

\section{Conclusions}

The paper analyzes the problem state of a typical small urban settlement in the Russian Federation, which is typical for most small urban settlements and single-industry towns. A number of common problems are identified: demographic problems associated with the outflow of the working-age population; the ruin or pre-crisis state of the city-forming industrial or mineral-mining enterprises, as a post-Soviet legacy of the introduction of the ideas of industrial communism of the USSR in modern Russia; poorly developed urban infrastructure, proceeding from the authoritarian style of the Soviet period; dilapidated 
housing stock; unpromising level of education in special professional institutions of working professions, tied to the city-forming (often irrelevant at the present stage), enterprise in a pre-crisis or on the verge of bankruptcy state; lack of jobs (problems with potential job growth, including); low wages of all categories of urban residents of a small urban settlement; falling and very low level of quality of life of the population; economic stagnation and a constant economic crisis of the size of an urban settlement, social problems: the depressive state of residents, life in a stressful state due to lack of money, activation of bad habits: alcoholism, drug addiction, etc. Using the TRIZ system operator, the author identifies the trend that characterizes the current state of small single-industry towns, identifies the reasons that prompted such a strategic state vector in the past, and concludes that the transfer of this trend to the future projection is denied. It was concluded that there is a need for a versatile vector of development of the future system - the rebirth of small urban agglomerations into medium-sized agglomerations: moving away from single-industry towns as a result of the introduction of several types of production facilities [15-16], in parallel with the development of a comfortable urban environment to improve the quality of life of residents and loyalty to the small homeland; and also it is offered a thorough study of the internal potential of the region of a small urban settlement, creation of advertising and PR-actions, on the basis of which there is an opportunity to develop new directions of domestic tourism in the Russian Federation, which will be an additional source of replenishment of the treasury of the urban agglomeration.

\section{References}

1. L. Richman, Improving Your Project Management Skills, 224 (AMACOM Division of American Management Association, 2011)

2. T. Theeboom, B. Beersma, A.E.M. van Vianena, The Journal of Positive Psychology, 9(1) (2013) doi:10.1080/17439760.2013.837499

3. L. Homans, Coaching Meridian, http://www.officialmeproject.com.au/why use a personal success life coach .html. (last accessed 2020/11/23)

4. M. Atkinson, Creating Transformational Metaphors, 161 (Exalon Publishing, Vancouver, 2013)

5. I. Ilevbare, D. Probert, R. Phaal, Technovation, 33, 30-37 (2013)

6. L. Chechurin, Y. Borgianni, Understanding, Computers in Industry, 82, 119-134 (2016)

7. L. Fiorineschi, F. S. Frillici, F. Rotini, Computers in Industry, 94, 1-15 (2018)

8. Z. Dawn, Hodges Use generational theory as a guide to understanding college students https://onlinelibrary.wiley.com/doi/full/10.1002/dap.30653 (last accessed 2020/11/23)

9. R. Boettcher, L. Helm A, Human Service Organizations: Management, Leadership \& Governance, 42, $353-358$

https://www.tandfonline.com/doi/full/10.1080/23303131.2018.1500974

10. A.D. Khavanskiy, J.Y. Merinova, A.S. Orlinskiy, O.A. Khoroshev, Y.N. Merinov,

World Applied Sciences Journal, 5, 679-682 (2014)

11. V. Tinyakova, E. Alpatova, I. Boldyreva, "Smart Technologies" for Society, State and

Economy, ISC: Institute of Scientific Communications Conference, 155, 1381-1388 (2020) doi.org/10.1007/978-3-030-59126-7_151.

12. E. Khalimon, AV. Vykhodtsev, "Smart Technologies" for Society, State and Economy, ISC: Institute of Scientific Communications Conference, 155, 1340-1347 (2020) doi.org/10.1007/978-3-030-59126-7_151.

13. A. Belinsky, V. Afanasev, "Smart Technologies" for Society, State and Economy, ISC: Institute of Scientific Communications Conference, 155, 1348-1355 (2020)

doi.org/10.1007/978-3-030-59126-7_151. 
14. E. Panfilova, V.Borisova, H. Raza "Smart Technologies" for Society, State and Economy, ISC: Institute of Scientific Communications Conference, 155, 1356-1365 (2020) doi.org/10.1007/978-3-030-59126-7_151. 15. D. Morkovkin, A. Gibadullin, B. Safarov, E. Alpatova, IOP Conference Series: Materialas Science and Engineering, 537, 42013 (2020)

16. E. Kamchatova, A. Bobryshev, O. Gudkova, "Smart Technologies" for Society, State and Economy, ISC: Institute of Scientific Communications Conference, 155, 1397-1405 (2020) doi.org/10.1007/978-3-030-59126-7_151. 